\title{
Insulin Resistance, Body Mass Index and Coronary Atherosclerotic Stenosis in Obese Adults
}

\section{Nianrong Zhang}

China-Japan Friendship Hospital https://orcid.org/0000-0002-5551-6114

\section{Yumeng Liu}

Beijng Huaxin Hospital First Hospital of Tsinghua University

\section{Guoshan Yang}

Beijng Huaxin Hospital First Hospital of Tsinghua University

\section{Biao Zhou}

China-Japan Friendship Hospital

\section{Guanming Qi}

Tufts Medical Center

Jianan Yu

Beijing Friendship Hospital

\section{Zhaoyang Yan}

Hebei Medical University Fourth Affiliated Hospital

Huanmei Liu

Cancer Hospital Chinese Academy of Sciences

Hua Meng ( $\nabla$ menghua_center@163.com )

\section{Original investigation}

Keywords: Obesity, Coronary atherosclerotic stenosis, Coronary computed tomography angiography, Insulin resistance

Posted Date: June 16th, 2020

DOl: https://doi.org/10.21203/rs.3.rs-28915/v1

License: (c) (1) This work is licensed under a Creative Commons Attribution 4.0 International License. Read Full License 


\section{Abstract}

Background: Obesity is associated with an increased risk of all-cause mortality. Mortality related to excess body weight occurs mostly due to coronary artery disease(CAD). This study is to observe the prevalence of coronary atherosclerotic stenosis in obese young-middle adults and outcomes of coronary stenosis in patients with obesity after metabolic surgery.

Methods: Patients with obesity undergoing metabolic surgery were included from December 2015 to June 2017. Coronary computed tomography angiography(CTA) was examined preoperatively. Patients were divided into the stenosis group and the non-stenosis group and differences in clinical indicators and Homeostasis model assessment insulin resistance(HOMA-IR)were compared between the two groups. After metabolic surgery, the clinical indicators and severity of coronary stenosis were compared with those before metabolic surgery.

Results: Among 217 consecutive obese patients with a mean body mass index(BMI) of $37.92 \pm 6.14 \mathrm{~kg} / \mathrm{m}^{2}$, $58(26.72 \%)$ patients were diagnosed with coronary atherosclerotic stenosis. Compared with the nonstenosis group, patients in the stenosis group had a more elder age, higher rates of male, smoking, hypertension and type 2 diabetes mellitus(T2DM), and higher levels of glycated haemoglobin(HbA1C), fasting blood glucose(FBG),fasting C-peptide and HOMA-IR $(P<0.05)$. While there was no significant difference in BMI, waist circumstance $(W C)$, serum lipid levels $(P \& 0.05)$. The multivariate binomial logistic regression analysis showed that the age $(\beta=0.070, O R=1.073,95 \% \mathrm{Cl} 1.028$ 1.120, $P<0.001)$,smoking( $\beta=1.371, \mathrm{OR}=3.941,95 \% \mathrm{Cl} 1.257-12.357, P=0.019)$, and $\mathrm{HOMA}-\mathrm{IR}(\beta=0.040$, $\mathrm{OR}=1.041,95 \% \mathrm{Cl} 1.000-1.083, P=0.047)$ were independent risk factors of coronary stenosis. After metabolic surgery, coronary stenosis relieved in $11 / 19$ cases $(57.89 \%)$, in which 9 cases got complete remission; coronary stenosis was aggravated in one case and remained the same in another one case.

Conclusions: HOMA-IR, as well as age and smoking, is an independent risk factor for CAD in obese patients. Metabolic surgery is possibly helpful to reverse mild to moderate coronary atherosclerotic stenosis in patients with obesity.

\section{Background}

Obesity is an important cause of metabolic syndrome (including dyslipidemia, hypertension and hyperglycemia), together with smoking, insulin resistance, inflammatory changes and vascular endothelial damage, which constitute risk factors for coronary artery disease(CAD). For overweight/obese patients, $9.60 \%-13.97 \%$ of male patients and $11.13 \%-19.22 \%$ of female patients had CAD [1]. According to a study of nearly 70 million people published by the global burden of disease study, obesity accounted for $7.1 \%$ of all deaths in 2015 , with cardiovascular disease accounting for $41.4 \%$;cardiovascular disease(CVD) is also the leading cause of death among overweight people, at 23.9\%[2]. With the increase of obese patients, the prevalence will be higher. 
Obesity, especially central obesity is linked to insulin resistance[3]. Some studies suggest that insulin resistance is associated with CAD in type 1 diabetes mellitus(T1DM)[4], type 2 diabetes mellitus(T2DM) [5] and non-diabetic subjects[6-8]. However, there was less studies about the association of insulin resistance and CAD in obese population.

Interesting, there is a hot debate on the controversial points on the obesity paradox in patients with $\mathrm{CAD}[9-11]$.It appears to be an obesity paradox that patients with body weight index(BMI) in the range of 30 to $34 \mathrm{~kg} / \mathrm{m} 2$ have a protective effect against cardiovascular diseases. While a recent meta-analysis found that compared with metabolically healthy normal-weight individuals are at increased risk for adverse long-term CVD events even in the absence of the metabolic abnormalities, suggesting there is no healthy pattern of increased weight[12]. Besides, a recent report indicated that weight loss is associated with significantly higher incidence of adverse cardiovascular outcomes in patients with coronary heart disease[13]. Thus, in the present study we sought to investigate the interplay of insulin resistance, BMI and CAD in obese young-middle aged adults and outcomes of metabolic surgery on coronary stenosis in patients with obesity.

\section{Methods}

\section{Patient selection}

Obese patients who underwent coronary computed tomography angiography (CTA) on a dual-source CT scanner before metabolic surgery from December 2015 to June 2017 were respectively included. The inclusion criteria was a, patients aged $18-59$ years old; $b$, patients with $B M I \geq 28 \mathrm{Kg} / \mathrm{m} 2$; c, patients with detailed medical record and distinct CTA images; $d$, patients without malignant tumors and other diseases which affect the body weight. This study was approved by the Research Ethics Committee of Beijing Friendship Hospital, and written informed consent was obtained from all patients.

\section{Data collection}

Clinical characteristics included age, sex, BMI, height, weight, waist circumference(WC), hypertension, T2DM, cigarette smoking, hyperlipidemia, creatinine, $75 \mathrm{~g}$ oral glucose tolerance test (OGTT) results, et al. Coronary atherosclerotic stenosis was defined as the presence of any atherosclerotic lesion $(>1 \%$ stenosis) in one or more coronary artery segments. According to coronary stenosis or not, the patients were divided into two groups, the stenosis group and the non-stenosis group.

\section{Surgical therapy and follow-up}

The patients who met the surgical indications in surgical treatment guidelines for obesity and T2DM in China (2014)[14], were preformed metabolic surgery(sleeve gastrectomy and Roux-en-Y gastric 
bypass).CTA was rechecked 1 year after surgery, and OGTT and other clinical indicators were tested again.

\section{Statistical analysis}

All statistical calculations were performed using SPSS25.0. Continuous variables are displayed as means \pm standard deviations(SDs) or medians (interquartile ranges) and categorical variables as numbers (percentages). Differences between the stenosis group and the non-stenosis group were determined by independent-samples T Test or nonparametric tests according to the Normality. Differences between pre and post-metabolic surgery were analyzed by Paired-samples T Test. A multivariable binomial logistic regression analysis was performed to detect associations of age, sex, smoking, hypertension, $\mathrm{T} 2 \mathrm{DM}, \mathrm{BMI}, \mathrm{HbA} 1 \mathrm{C}$ and HOMA-IR with the odds of having coronary stenosis. Statistical significance was set at $p<0.05$.

\section{Results}

\section{Baseline characteristics}

A total of 217 consecutive obese patients(male:23.5\%) had a mean age of $33.62 \pm 8.91$ years(range 1859 years) and a mean BMl of $37.92 \pm 6.14 \mathrm{~kg} / \mathrm{m}^{2}$ (range $28.0-60.5 \mathrm{~kg} / \mathrm{m}^{2}$ ). They were divided into two groups, 58 cases(26.72\%) in the stenosis group and 159 cases(73.28\%) in the non-stenosis group.

\section{Association of clinical indicators with coronary stenosis}

Baseline clinical characteristics in the non-stenosis group and the stenosis group were showed in Table1.Compared with the non-stenosis group, patients in the stenosis group had a more elder age $(P<$ $0.001)$, higher rates of men $(P=0.040)$, smoking $(P<0.001)$, hypertension $(P<0.010)$ and T2DM $(P=0.002)$, elevated levels of glycated haemoglobin(HbA1C) $(P=0.006)$, fasting blood glucose(FBG, $P<0.001)$ and fasting C-peptide $(P=0.012)$ and Homeostasis model assessment insulin resistance(HOMA-IR, $P=0.038$ ) (Table 1). 
Table 1 Baseline characteristics in the non-stenosis group and the stenosis group

\begin{tabular}{|c|c|c|c|c|}
\hline & $\begin{array}{l}\text { Non-stenosis group } \\
(n=159)\end{array}$ & $\begin{array}{l}\text { Stenosis group } \\
(n=58)\end{array}$ & All $(n=217)$ & $P$ values \\
\hline Age(years) & $32.05 \pm 8.00$ & $37.93 \pm 9.89$ & $33.62 \pm 8.91$ & $<0.001$ \\
\hline Sex(Male\%) & 19.5 & 32.7 & 23.5 & 0.040 \\
\hline Smoking(\%) & 5.1 & 24.6 & 10.6 & $<0.001$ \\
\hline Height(cm) & $166.62 \pm 7.69$ & $167.47 \pm 7.38$ & $166.85 \pm 7.60$ & 0.403 \\
\hline Weight(Kg) & $104.97 \pm 21.59$ & $106.64 \pm 21.3$ & $105.42 \pm 21.48$ & 0.676 \\
\hline $\mathrm{BMI}(\mathrm{Kg} / \mathrm{cm} 2 \rrbracket$ & $37.94 \pm 5.67$ & $38.06 \pm 7.23$ & $37.92 \pm 6.14$ & 0.605 \\
\hline $\mathrm{WC}(\mathrm{cm})$ & $113.69 \pm 14.40$ & $115.19 \pm 14.76$ & $114.09 \pm 14.47$ & 0.682 \\
\hline T2DM(\%) & 30.8 & 54.4 & 37.3 & 0.002 \\
\hline $\mathrm{HbA1C}$ & $6.24 \pm 1.48$ & $6.87 \pm 1.85$ & $6.41 \pm 1.40$ & 0.006 \\
\hline $\mathrm{FBG}(\mathrm{mmol} / \mathrm{L})$ & $5.51 \pm 2.94$ & $6.73 \pm 3.28$ & $5.84 \pm 3.07$ & $<0.001$ \\
\hline Fasting Insulin $(\mu \mathrm{IU} / \mathrm{mL})$ & $27.81 \pm 27.16$ & $36.55 \pm 40.58$ & $30.19 \pm 31.52$ & 0.461 \\
\hline Fasting C-peptide(ng/mL) & $3.18 \pm 2.63$ & $4.13 \pm 3.65$ & $3.43 \pm 2.96$ & 0.012 \\
\hline HOMA-IR & $4.25(5.60)$ & $6.73(9.93)$ & $4.60(6.52)$ & 0.038 \\
\hline Hypertension(\%) & 14.0 & 29.3 & 18.4 & 0.010 \\
\hline $\mathrm{SBP}(\mathrm{mmHg})$ & $129.89 \pm 13.66$ & $130.78 \pm 12.20$ & $130.13 \pm 13.26$ & 0.598 \\
\hline $\operatorname{ALT}(\mathrm{IU} / \mathrm{L})$ & $44.04+41.25$ & $43.40 \pm 29.04$ & $43.87 \pm 38.74$ & 0.302 \\
\hline TBIL (umol/L) & $10.16 \pm 4.37$ & $10.07 \pm 4.12$ & $10.08 \pm 9.50$ & 0.851 \\
\hline $\mathrm{TC}(\mathrm{mmol} / \mathrm{L})$ & $4.99 \pm 1.04$ & $5.18 \pm 1.64$ & $5.05 \pm 1.20$ & 0.978 \\
\hline $\mathrm{TG}(\mathrm{mmol} / \mathrm{L})$ & $2.20 \pm 2.38$ & $2.67 \pm 2.76$ & $2.28 \pm 2.23$ & 0.169 \\
\hline $\mathrm{HDL}-\mathrm{C}(\mathrm{mmol} / \mathrm{L})$ & $1.07 \pm 0.20$ & $1.06 \pm 0.25$ & $1.06 \pm 0.21$ & 0.544 \\
\hline LDL-C (mmol/L) & $2.87 \pm 0.67$ & $2.90 \pm 0.75$ & $2.90 \pm 0.68$ & 0.733 \\
\hline Uric Acid (umol/L) & $407.40 \pm 99.80$ & $407.95 \pm 85.90$ & $407.71 \pm 97.24$ & 0.746 \\
\hline Creatinine(umol/L) & $67.44 \pm 12.59$ & $71.09 \pm 12.67$ & $69.02 \pm 11.67$ & 0.094 \\
\hline
\end{tabular}


The binomial multivariate logistic regression analysis showed that the age $(\beta=0.070,0 R=1.073,95 \% \mathrm{Cl}$ 1.028-1.120, $P<0.001)$, smoking( $\beta=1.371, \mathrm{OR}=3.941,95 \% \mathrm{Cl} 1.257-12.357, P=0.019)$, and HOMA$\mathrm{IR}(\beta=0.040, \mathrm{OR}=1.041,95 \% \mathrm{Cl} 1.000-1.083, P=0.047)$ were independent risk factors of coronary stenosis. While sex, $\mathrm{BMI}$, rates of hypertension and $\mathrm{DM}$, and $\mathrm{HbA1C}$ had no significantly association with risks of having coronary stenosis(table2).

Table 2 Multivariate logistic regression analysis of presence of coronary stenosis with risk factors

\begin{tabular}{|lllll|}
\hline & $\boldsymbol{\beta}$ & P values & OR & 95\% Cl for OR \\
\hline Age & 0.070 & 0.001 & 1.073 & $1.028-1.120$ \\
\hline sex(Female=1) & -0.118 & 0.791 & 0.888 & $0.371-2.128$ \\
\hline Smoking(1) & 1.371 & 0.019 & 3.941 & $1.257-12.357$ \\
\hline Hypertension(1) & 0.083 & 0.860 & 1.086 & $0.431-2.738$ \\
\hline T2DM(1) & 0.522 & 0.301 & 1.685 & $0.627-4.525$ \\
\hline BMI & 0.032 & 0.265 & 1.032 & $0.976-1.092$ \\
\hline HbA1C & -0.030 & 0.851 & 0.970 & $0.707-1.332$ \\
\hline HOMA-IR & 0.040 & 0.047 & 1.041 & $1.000-1.083$ \\
\hline Constant & -5.123 & 0.004 & 0.006 & \\
\hline
\end{tabular}

To detect the relationship of HOMA-IR and BMI, further association was analyzed. The Pearson association analysis showed there was no linear association of HOMA-IR and BMI( $P=0.231$, Fig.1).

\section{Metabolic and coronary outcomes after metabolic surgery}

Table3 showed that1-year post metabolic surgery, BMI, blood pressure, and levels of ALT, lipids and uric acid, HbA1C and HOMA-IR were significantly improved (Pख0.05). Besides, the ratios of diabetes and hypertension were totally relieved(100\%). 
Table3 Comparison of clinical indexes of 19 patients before and after metabolic surgery

\begin{tabular}{|llll|}
\hline & Baseline & 1 year after surgery & PValues \\
\hline BMI(Kg/m² & $38.89 \pm 6.95$ & $27.83 \pm 3.30$ & $<0.001$ \\
\hline T2DM(\%) & $36.7 \%$ & $0.0 \%$ & - \\
\hline HbA1C(\%) & $6.44 \pm 1.63$ & $5.42 \pm 0.59$ & 0.026 \\
\hline HOMA-IR & $7.95 \pm 7.81$ & $2.06 \pm 1.58$ & 0.018 \\
\hline Hypertension(\%) & $24.2 \%$ & $0.0 \%$ & - \\
\hline SBP(mmHg) & $130.66 \pm 14.45$ & $123.20 \pm 14.81$ & 0.11 \\
\hline ALT(IU/L) & $45.94 \pm 38.41$ & $17.75 \pm 10.23$ & 0.004 \\
\hline TBIL (umol/L) & $10.08 \pm 4.24$ & $12.01 \pm 4.06$ & 0.095 \\
\hline TC(mmol/L) & $5.02 \pm 1.13$ & $4.41 \pm 0.92$ & 0.036 \\
\hline TG(mmol/L) & $2.35 \pm 2.35$ & $0.92 \pm 0.39$ & 0.016 \\
\hline HDL-C(mmol/L) & $1.04 \pm 0.21$ & $1.25 \pm 0.31$ & 0 \\
\hline LDL-C(mmol/L) & $2.87 \pm 0.66$ & $2.38 \pm 0.72$ & 0.004 \\
\hline Uric Acid (umol/L) & $408.66 \pm 97.61$ & $335.38 \pm 66.23$ & 0.003 \\
\hline
\end{tabular}

19 patients rechecked coronary CTA 1 year after metabolic surgery. Among those patients, coronary stenosis was relieved in $11 / 19$ cases $(57.89 \%)$, in which a complete remission in 9 cases( 1 case was showed in Fig. 2); coronary stenosis was aggravated in 1 case $(5.26 \%$, ), who had $80 \%$ of stenosis in the left anterior descending branch; coronary stenosis remained the same in 1 case (5.26\%). 6 cases (31.58\%) without coronary stenosis pre-surgery had no progression.

\section{Discussion}

Obesity is associated with an increased risk of all-cause mortality. Mortality related to excess body weight occurred mostly due to coronary artery disease. Compared to subjects with normal weight or overweight, obesity is an independent risk factor for CAD. In this study, it was HOMA-IR not BMI that was associated with presence of $C A D$, independent of the presence of $D M$ and hypertension, age, sex, smoking, $B M I$ and $\mathrm{HbA} 1 \mathrm{C}$. The prevalence of CAD in was $26.72 \%$ among the studied young-middle obese adults.Data from other studies ranged from 4.5-52\%[15-17], owing to differences of race, age, sex ratio, radiology examination methods (CTA or angiography) or definitions of CAD. 
However, the relationship between $\mathrm{BMI}$, other cardiovascular risk factors, and the risk of CAD are complex. There is an ongoing debate in light of this conflicting result. In subgroup analysis by region or ethnicity, significant differences in all of the ethnic groups and regions was not observed[16]. In this study, it was HOMA-IR not BMI that associated with CAD in obese adults with a BMI of 28 to $60 \mathrm{Kg} / \mathrm{m}^{2}$. Obesity and/or an increased BMI are independently associated with greater risk of insulin resistance, metabolic syndrome, diabetes, hypertension, and dyslipidemia, and these complications may be more important markers of CAD risk than obesity/BMI alone. Another possible reason may be attributed to the inherent limitations of BMI as a marker of obesity or severe obesity, without exactly reflecting body fatness and lean body mass. For example, a person with increased muscle mass would have the same BMI as a person with increased fat percentage. Thirdly, we suppose that once a person's BMIख28(Chinese guideline) or $30 \mathrm{Kg} / \mathrm{m}^{2}$, his/her risk for CAD may be higher, irrespective of the different degrees of obesity, and the risks should be determined by HOMA-IR and other insulin resistance factors. Finally, the sample of this study was a limitation, which weak the strength of the association. And associations of BMI with extent of coronary stenosis hadn't been studied.

Insulin resistance is a major component of obesity, metabolic syndrome, T2DM and CAD. HOMA-IR is a commonly used marker of insulin resistance which incorporates both glucose and insulin concentrations. An meta-analysis of 65 studies published in 2012, which included 516,325 participants, also revealed that insulin resistance, evaluated by HOMA-IR, was a good predictor for cardiovascular disease[8].In this study, HOMA-IR was independently associated with having coronary stenosis in obese patients. While the Pearson analysis showed no association between HOMA-IR and BMI. It illustrates why the two factors did not relate to the risks of CAD simultaneously. This indicates that maybe we should pay more attention to insulin resistance than $\mathrm{BMI}$ alone to evaluate the CAD risks in obese patients.

Currently, statins are generally considered as important drugs that can improve the condition of coronary plaque. According to a study published by JACC in 2018 involving more than 3,500 patients who used coronary CTA to evaluate coronary artery plaques, statins can delay the progression of coronary artery plaques and facilitate the transformation of plaques to stable plaques but cannot reverse the degree of coronary artery stenosis[18]. As shown in Table 3, metabolic surgery has significant remission effect on various risk factors of CAD. This could be the cause of remission in coronary stenosis. As is proved by other studies[19], the mechanism might be: a) By limiting food intake (all types of metabolic surgery) and nutrient intake (gastric bypass surgery), thereby promoting the remission of metabolic syndrome and improving cardiovascular conditions, b) Studies have shown that metabolic surgery simultaneously improves gastrointestinal hormones, intestinal flora, central nervous system and other systemic factors, thus improving metabolic syndrome. Metabolic surgery is likely to be a promising therapeutic approach for obese patients with CAD except weight loss. However, the number of follow-up cases was too few, which needs multi-centered large sample studies to yield stronger findings.

Limitation of our study: a) There was a bias in sex ratio(male,32.76\%vs $19.50 \%$ respectively),owing to the women had more willing to visit Bariatric Clinics. While men were more susceptible to CAD. As we know, men usually have higher BMI and weight, so the strength of the association might be weakened; $b$ ) 
Another shortage was the small sample size, especially in the postoperative cases, and the limited sample size of our study did not allow for subgroup analysis

\section{Conclusion}

Age, smoking and HOMA-IR are independent risk factors for CAD. Compared with BMI, insulin resistance may be a better predictor for risks of CAD in obese adults with $B M I$ at a range of 28 to $60 \mathrm{Kg} / \mathrm{m}^{2}$. Metabolic surgery may possibly reverse mild to moderate coronary atherosclerotic stenosis in patients with obesity. It needs multi-centered large sample studies to yield stronger findings.

\section{Abbreviations}

\begin{tabular}{|ll|}
\hline CAD & coronary artery disease \\
\hline CTA & computed tomography angiography \\
\hline HOMA-IR & Homeostasis model assessment insulin resistance \\
\hline BMI & body mass index \\
\hline T2DM & type 2 diabetes mellitus \\
\hline HbA1C & glycated haemoglobin \\
\hline FBG & fasting blood glucose \\
\hline WC & waist circumstance \\
\hline CVD & cardiovascular disease \\
\hline T1DM & type 1 diabetes mellitus \\
\hline OGTT & oral glucose tolerance test \\
\hline SD & standard deviation \\
\hline SBP & systolic blood pressure \\
\hline ALT & alanine transaminase \\
\hline TBIL & total bilirubin \\
\hline TC & total cholesterol \\
\hline TG & triglyceride \\
\hline HDL-C & high density lipoprotein cholesterol \\
\hline LDL-C & low density lipoprotein cholesterol \\
\hline
\end{tabular}

\section{Declarations}




\section{Ethics approval and consent to participate}

Participants from both cohorts gave written informed consent and study protocols were approved by the ethics committee of Beijing Friendship Hospital.

\section{Consent for publication}

All authors read and approved the final manuscript.

\section{Availability of data and materials}

Yes.

\section{Competing interests}

The authors declare no competing interests in relation to this work.

\section{Funding}

This work was supported by the Beijing Municipal Science \& Technology Commission (Nos.Z151100004015065).

\section{Authors' contributions}

NRZ, YML and HM designed the study. YML, GSY, JNY and HML acquired data. NRZ, BZ, GMQ and ZYY analyzed and interpreted the data. NRZ and YML wrote the manuscript. HM revised the manuscript. All authors reviewed/edited the manuscript.

\section{Acknowledgements}

None.

\section{References}

1. Must A, Spadano J, Coakley EH, Field AE, Colditz G, and Dietz WH, The disease burden associated with overweight and obesity. JAMA. 1999; 282(16):1523-9.

2. Collaborators GBDO, Afshin A, Forouzanfar MH, Reitsma MB, Sur P, Estep K, Lee A, Marczak L, Mokdad AH, Moradi-Lakeh M, Naghavi M, Salama JS, Vos T, Abate KH, Abbafati C, Ahmed MB, Al-Aly 
Z, Alkerwi A, Al-Raddadi R, Amare AT, Amberbir A, Amegah AK, Amini E, Amrock SM, Anjana RM, Arnlov J, Asayesh H, Banerjee A, Barac A, Baye E, Bennett DA, Beyene AS, Biadgilign S, Biryukov S, Bjertness E, Boneya DJ, Campos-Nonato I, Carrero JJ, Cecilio P, Cercy K, Ciobanu LG, Cornaby L, Damtew SA, Dandona L, Dandona R, Dharmaratne SD, Duncan BB, Eshrati B, Esteghamati A, Feigin VL, Fernandes JC, Furst T, Gebrehiwot TT, Gold A, Gona PN, Goto A, Habtewold TD, Hadush KT, Hafezi-Nejad N, Hay SI, Horino M, Islami F, Kamal R, Kasaeian A, Katikireddi SV, Kengne AP, Kesavachandran CN, Khader YS, Khang YH, Khubchandani J, Kim D, Kim YJ, Kinfu Y, Kosen S, Ku T, Defo BK, Kumar GA, Larson HJ, Leinsalu M, Liang X, Lim SS, Liu P, Lopez AD, Lozano R, Majeed A, Malekzadeh R, Malta DC, Mazidi M, McAlinden C, McGarvey ST, Mengistu DT, Mensah GA, Mensink GBM, Mezgebe HB, Mirrakhimov EM, Mueller UO, Noubiap JJ, Obermeyer CM, Ogbo FA, Owolabi MO, Patton GC, Pourmalek F, Qorbani M, Rafay A, Rai RK, Ranabhat CL, Reinig N, Safiri S, Salomon JA, Sanabria JR, Santos IS, Sartorius B, Sawhney M, Schmidhuber J, Schutte AE, Schmidt MI, Sepanlou SG, Shamsizadeh M, Sheikhbahaei S, Shin MJ, Shiri R, Shiue I, Roba HS, Silva DAS, Silverberg JI, Singh JA, Stranges S, Swaminathan S, Tabares-Seisdedos R, Tadese F, Tedla BA, Tegegne BS, Terkawi AS, Thakur JS, Tonelli M, Topor-Madry R, Tyrovolas S, Ukwaja KN, Uthman OA, Vaezghasemi M, Vasankari T, Vlassov VV, Vollset SE, Weiderpass E, Werdecker A, Wesana J, Westerman R, Yano Y, Yonemoto N, Yonga G, Zaidi Z, Zenebe ZM, Zipkin B and Murray CJL, Health Effects of Overweight and Obesity in 195 Countries over 25 Years. N Engl J Med. 2017; 377(1):13-27.

3. Ormazabal V, Nair S, Elfeky O, Aguayo C, Salomon C, and Zuniga FA, Association between insulin resistance and the development of cardiovascular disease. Cardiovasc Diabetol. 2018; 17(1):122.

4. Dabelea D, Kinney G, Snell-Bergeon JK, Hokanson JE, Eckel RH, Ehrlich J, Garg S, Hamman RF, Rewers $\mathrm{M}$, and Coronary Artery Calcification in Type 1 Diabetes S, Effect of type 1 diabetes on the gender difference in coronary artery calcification: a role for insulin resistance? The Coronary Artery Calcification in Type 1 Diabetes (CACTI) Study. Diabetes. 2003; 52(11):2833-9.

5. Srinivasan MP, Kamath PK, Manjrekar PA, Unnikrishnan B, Ullal A, Kotekar MF, and Mahabala C, Correlation of severity of coronary artery disease with insulin resistance. N Am J Med Sci. 2013; 5(10):611-4.

6. Vafaeimanesh J, Parham M, Norouzi S, Hamednasimi P, and Bagherzadeh M, Insulin resistance and coronary artery disease in non-diabetic patients: Is there any correlation? Caspian J Intern Med. 2018; 9(2):121-26.

7. Mossmann M, Wainstein MV, Goncalves SC, Wainstein RV, Gravina GL, Sangalli M, Veadrigo F, Matte R, Reich R, Costa FG, and Bertoluci MC, HOMA-IR is associated with significant angiographic coronary artery disease in non-diabetic, non-obese individuals: a cross-sectional study. Diabetol Metab Syndr. 2015; 7:100.

8. Gast KB, Tjeerdema N, Stijnen T, Smit JW, and Dekkers OM, Insulin resistance and risk of incident cardiovascular events in adults without diabetes: meta-analysis. PLoS One. 2012; 7(12):e52036.

9. Dong SY and Zeng Q, Reply to: "Controversial points in the obesity paradox in patients with coronary artery disease". Atherosclerosis. 2018; 275:455-56. 
10. Eyuboglu M, Controversial points in the obesity paradox in patients with coronary artery disease. Atherosclerosis. 2018; 275:453-54.

11. Thomas G, Khunti K, Curcin V, Molokhia M, Millett C, Majeed A, and Paul S, Obesity paradox in people newly diagnosed with type 2 diabetes with and without prior cardiovascular disease. Diabetes Obes Metab. 2014; 16(4):317-25.

12. Kramer CK, Zinman B, and Retnakaran R, Are metabolically healthy overweight and obesity benign conditions?: A systematic review and meta-analysis. Ann Intern Med. 2013; 159(11):758-69.

13. Dong SY, Yan ST, Wang ML, Li ZB, Fang LQ, and Zeng Q, Associations of body weight and weight change with cardiovascular events and mortality in patients with coronary heart disease. Atherosclerosis. 2018; 274:104-11.

14. (CSMBS) CSfMBS, Surgery guideline for Chinese obesity and type 2 diabetes. Chin J Pract Surg. 2014; 34:301-06.

15. Otaki Y, Gransar H, Cheng VY, Dey D, Labounty T, Lin FY, Achenbach S, Al-Mallah M, Budoff MJ, Cademartiri F, Callister TQ, Chang HJ, Chinnaiyan K, Chow BJ, Delago A, Hadamitzky M, Hausleiter J, Kaufmann P, Maffei E, Raff G, Shaw LJ, Villines TC, Dunning A, Cury RC, Feuchtner G, Kim YJ, Leipsic $\mathrm{J}$, Berman DS, and Min JK, Gender differences in the prevalence, severity, and composition of coronary artery disease in the young: a study of 1635 individuals undergoing coronary CT angiography from the prospective, multinational confirm registry. Eur Heart $\mathrm{J}$ Cardiovasc Imaging. 2015; 16(5):490-9.

16. Labounty TM, Gomez MJ, Achenbach S, Al-Mallah M, Berman DS, Budoff MJ, Cademartiri F, Callister TQ, Chang HJ, Cheng V, Chinnaiyan KM, Chow B, Cury R, Delago A, Dunning A, Feuchtner G, Hadamitzky M, Hausleiter J, Kaufmann P, Kim YJ, Leipsic J, Lin FY, Maffei E, Raff G, Shaw LJ, Villines TC, and Min JK, Body mass index and the prevalence, severity, and risk of coronary artery disease: an international multicentre study of 13,874 patients. Eur Heart J Cardiovasc Imaging. 2013; 14(5):45663.

17. Ding L, Peng K, Lin L, Li M, Wang T, Dai M, Zhao Z, Xu M, Lu J, Chen Y, Wang W, Bi Y, Xu Y, and Ning $G$, The impact of fat distribution on subclinical coronary atherosclerosis in middle-aged Chinese adults. Int J Cardiol. 2017; 235:118-23.

18. Lee SE, Chang HJ, Sung JM, Park HB, Heo R, Rizvi A, Lin FY, Kumar A, Hadamitzky M, Kim YJ, Conte E, Andreini D, Pontone G, Budoff MJ, Gottlieb I, Lee BK, Chun EJ, Cademartiri F, Maffei E, Marques H, Leipsic JA, Shin S, Choi JH, Chinnaiyan K, Raff G, Virmani R, Samady H, Stone PH, Berman DS, Narula J, Shaw LJ, Bax JJ, and Min JK, Effects of Statins on Coronary Atherosclerotic Plaques: The PARADIGM Study. JACC Cardiovasc Imaging. 2018; 11(10):1475-84.

19. Michalsky MP, Inge TH, Simmons M, Jenkins TM, Buncher R, Helmrath $M$, Brandt ML, Harmon CM, Courcoulas A, Chen M, Horlick M, Daniels SR, Urbina EM, and Teen LC, Cardiovascular Risk Factors in Severely Obese Adolescents: The Teen Longitudinal Assessment of Bariatric Surgery (Teen-LABS) Study. JAMA Pediatr. 2015; 169(5):438-44. 
Figures

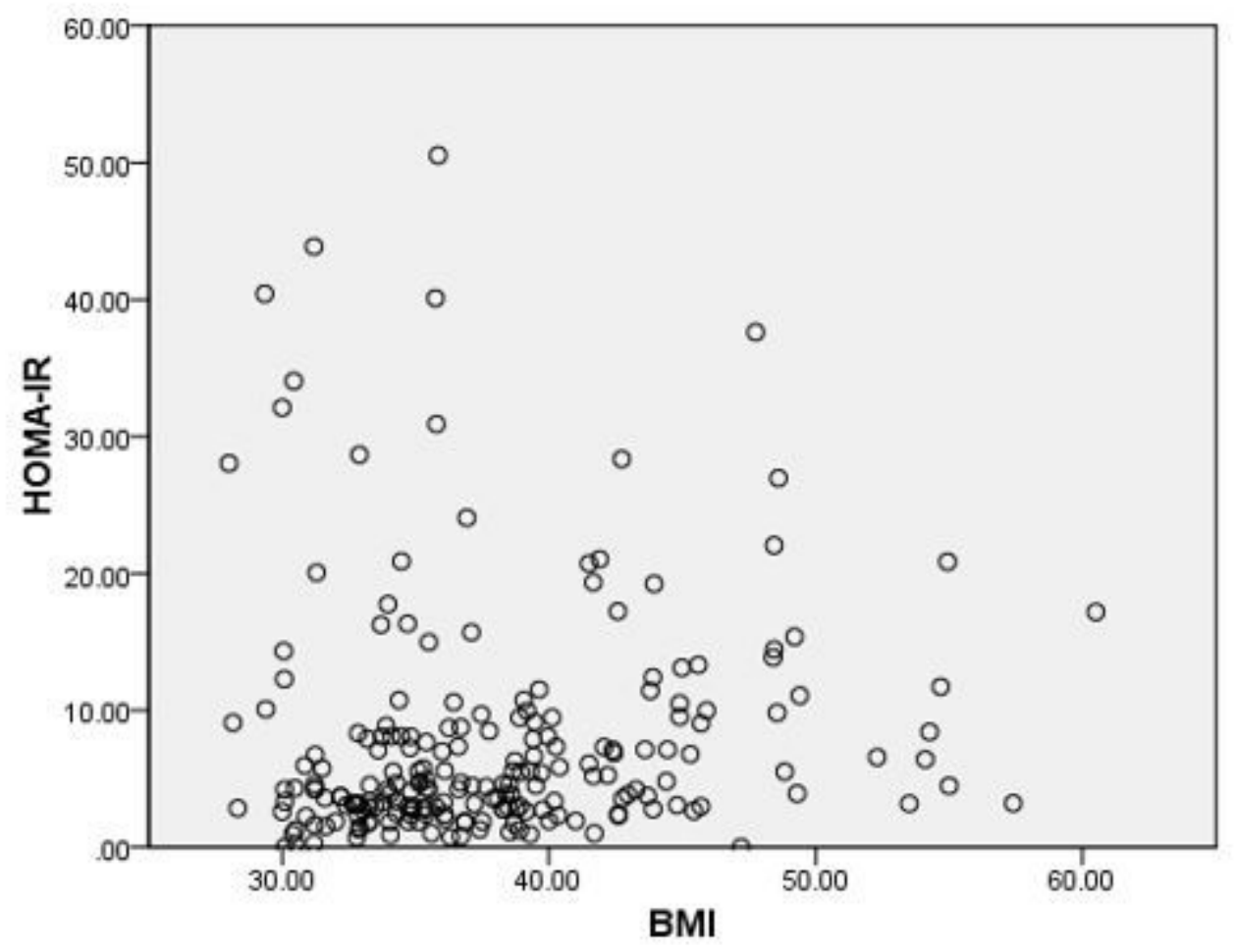

Figure 1

Scatter plot of HOMA-IR and BMI 

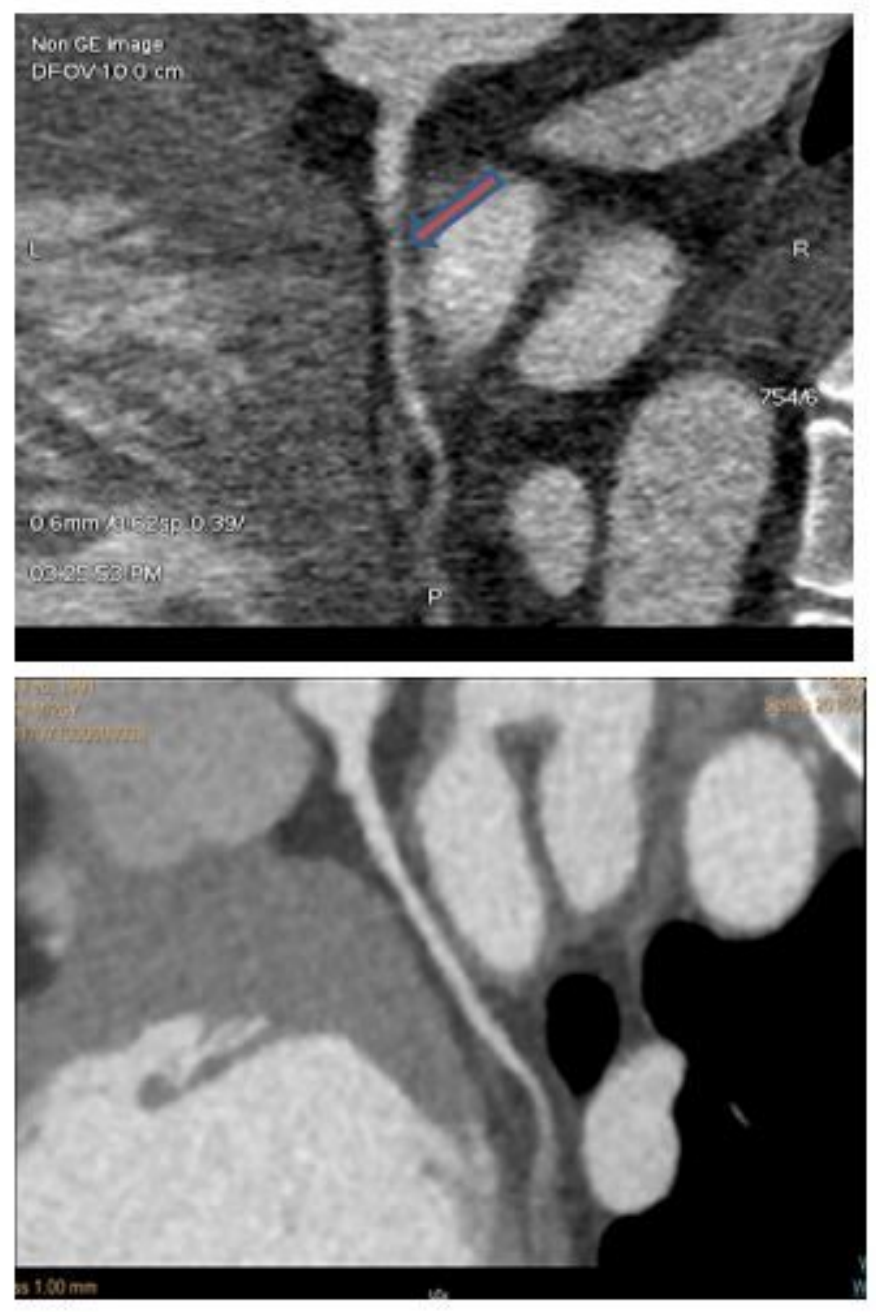

Figure 2

Coronary arterial stenosis was relieved in a 25 year-old male patient 1 year after metabolic surgery(the upper figure showed $65 \%$ stenosis in the left circumflex artery before surgery; the lower one showed no stenosis in the same position after metabolic surgery) 